\title{
Monitoring Surface-Water Quality in the Tongue River Watershed
}

\author{
While past and ongoing efforts have added substantially to our knowledge, sufficient data are not available \\ for full understanding of water resources and water quality in the Tongue River watershed.
}

Coal-bed methane (CBM) development is in the initial stages of exploration and production in the Tongue River watershed of southeastern Montana and northeastern Wyoming (fig. 1). In recent years, many State, Federal, and Tribal agencies and other entities have worked together to share information, communicate concerns, and coordinate datacollection activities for areas of potential CBM development. While past and ongoing efforts have added substantially to our scientific understanding, sufficient monitoring data are not available for full documentation of water resources and water quality in the watershed. As CBM development proceeds over the next 10 to 20 years, long-term monitoring will be needed to provide information to evaluate any changes or trends in surface-water quality and support informed decisions about resource management. For fiscal year 2004, Congress appropriated funding for the U.S. Geological Survey to initiate a comprehensive surfacewater-quality monitoring program in the Tongue River watershed. The goal of the program is to collect and disseminate water-quality data to stakeholders and the general public as well as to State and Federal agencies tasked with managing and regulating CBM development.

\section{Monitoring for the future}

The objectives of this monitoring program are to:

- collect data to document the current surface-water quality of the Tongue River and its major tributaries and detect changes, if any, over time, and

- provide real-time surface-waterquality information for parameters of greatest concern-particularly specific conductance and sodium adsorption ratio (SAR).

\section{Approach}

Establish monitoring network. A monitoring network consisting of eleven stations will be established during 2004 (fig. 1). Six mainstem monitoring stations will be on the Tongue River to identify downstream changes in water quality. Five stations will be on major tributaries to the Tongue River to document water quality in these smaller watersheds. Continuous streamflow and specificconductance data will be collected at each station.

Collect water-quality data. The mainstem Tongue River stations will be sampled approximately twice-monthly during the irrigation season (MarchOctober) and once-monthly for the rest of the year. The tributary stations will be sampled approximately 12 times per year, with more frequent sampling during the irrigation season. Water samples will be analyzed for major ions, nutrients, trace elements, and suspended sediment. Constituents of primary concern for analysis are those typically contained in CBM product water at relatively high concentrations. Examples of these constituents include sodium (a major ion), ammonia (a nutrient), and nitrate (another nutrient that forms when ammonia is exposed to oxygen). Trace elements, such as arsenic,
Figure 1. Water-quality sampling sites in the Tongue River watershed. All sites will have continuous streamflow gages and specific-conductance monitors. 
Sodium adsorption ratio (SAR) is a measure of the suitability of irrigation water for sustained soil and crop health. Water with a higher ratio is less suitable for irrigation. SAR values greater than 5-10 can indicate medium to high sodium hazard.

iron, manganese, and nickel, are of lesser concern because their concentrations generally are relatively low (Rice and Nuccio, 2000).

Develop real-time SAR estimates and measurement techniques. Providing real-time SAR information will be addressed in two ways. First, statistical relations between specific conductance and SAR will be examined for each station (fig. 2). If these relations are statistically meaningful, real-time estimates of SAR will be generated from continuous specificconductance data for each station. Second, recent technological advances have made possible the development of experimental instrumentation that can be placed in the field and provide automated measurements of the constituents (calcium, magnesium, and sodium) which are used to calculate SAR. One analyzer will be built, deployed, and tested during 2004. If that is successful, a second instrument will be deployed in 2005 .

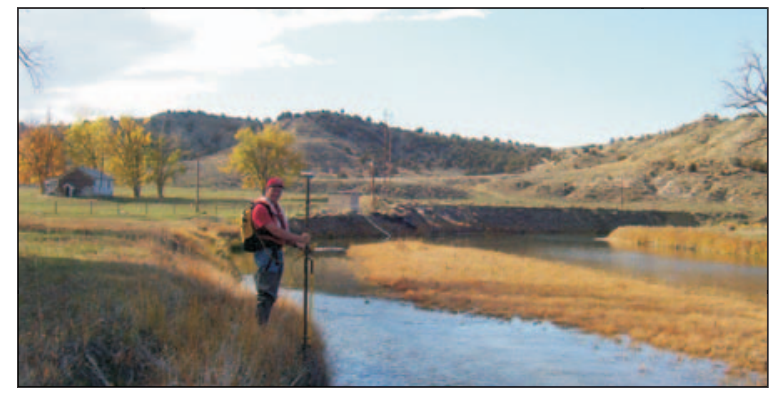

Tongue River at State Line, Montana (site 2, fig. 1).

Provide information to the public. All data collected at each station in the network will be made available on a dedicated web site developed just for this network:

(http://TongueRiverMonitoring.cr.usgs.gov/).

Streamflow and specific-conductance data will be provided in real time from satellite transmissions. Estimates of SAR at stations with sufficient data and reliable statistical relations also will be provided on the dedicated web site. Should the experimental SAR instrumentation prove successful, then SAR values calculated from direct field measurements of calcium, magnesium, and sodium will also be provided.

\section{Reference Cited}

Rice, C.A., and Nuccio, Vito, 2000, Water produced with coal-bed methane: U.S. Geological Survey Fact Sheet FS-156-00, 2 p.

By David A. Nimick

Tongue River at State Line (site 2, fig.1)

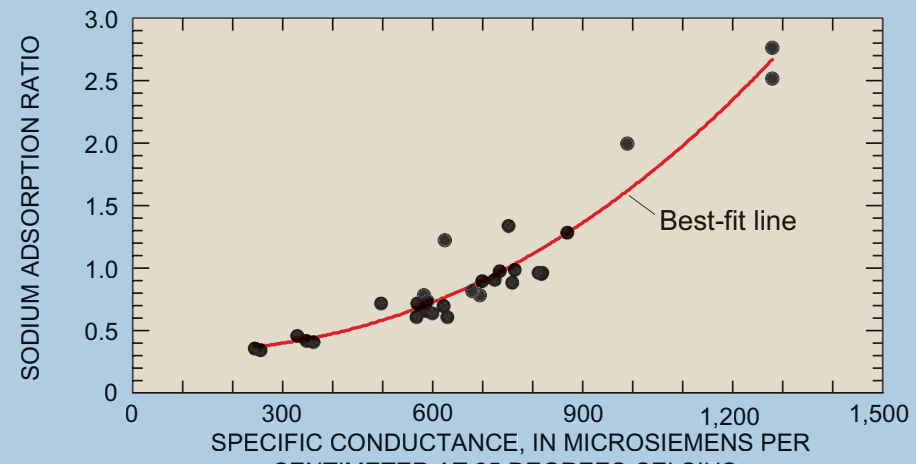
CENTIMETER AT 25 DEGREES CELSIUS

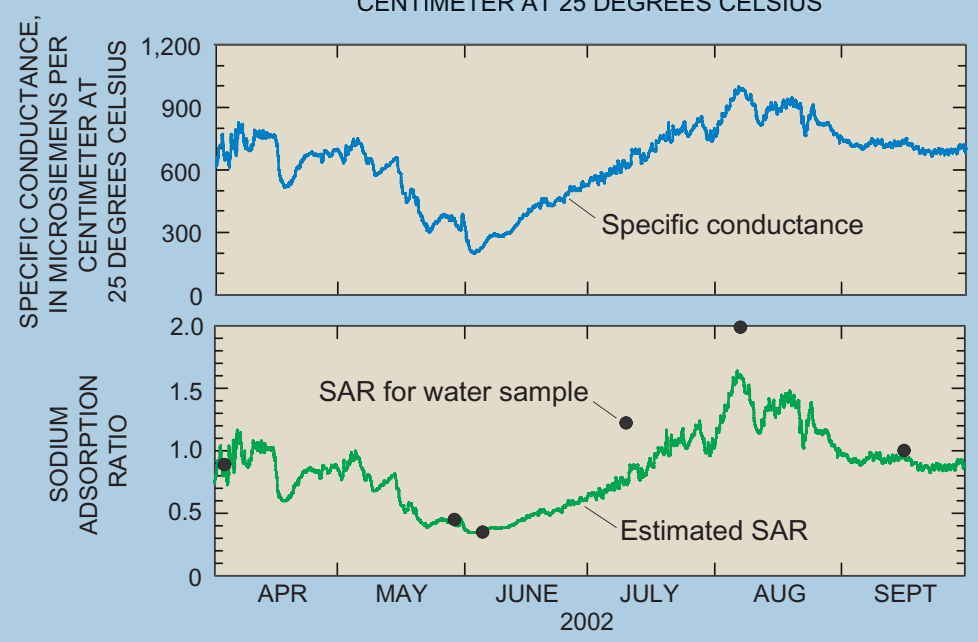

Figure 2. The sodium adsorption ratio (SAR) commonly can be estimated from specific conductance (SC). This figure provides an example of how this estimation could be accomplished. The estimation process starts with SC and SAR data for water samples collected at a site. For example, the upper graph shows the relation between SC and SAR for water samples collected during 1999-2002 at Tongue River at State Line (site 2, fig. 1). In the middle graph, continuous SC data collected at this site are shown for April-September 2002. The relation between SC and SAR determined in the upper graph can be applied to the continuous SC data (middle graph) to produce the continuous estimated SAR values shown in the lower graph.

To demonstrate the reliability of the estimation process, SAR values for individual water samples also are shown (solid circles) in the lower graph. Data for samples collected during April-June plot close to the estimated SAR line indicating that SAR might be reliably estimated from SC at this site during this period. However, the SAR values for the water samples collected in July-September are higher than the estimated values by as much as 30 percent. This difference between the calculated and estimated SAR values indicates that the relation developed in the upper graph is not as good at estimating SAR at this site for the summer as for the spring. Further research might lead to improvements in the ability to predict SAR from SC.

\section{For more information, contact:}

District Chief

U.S. Geological Survey 3162 Bozeman Avenue Helena, MT 59601 406-457-5900 or 1-888-ASK-USGS

\section{Please visit the USGS on the Internet:}

The USGS Montana District homepage is: http://mt.water.usgs.gov/

The USGS Tongue River monitoring program homepage is: http://TongueRiverMonitoring.cr.usgs.gov/

The National USGS homepage is: http://www.usgs.gov/ 